\title{
THEMATIC ANALYSIS OF JUAN SOLANA'S UPSIDE DOWN MOVIE
}

\author{
AN ARTICLE \\ Submitted as Partial Fulfillment of the Requirements \\ for the Degree of Sarjana Sastra
}

By:

VALDY RIFZKI

Registration Number.2123220038

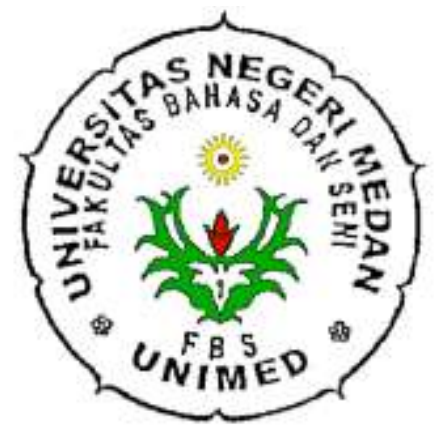

ENGLISH AND LITERATURE DEPARTMENT

FACULTY OF LANGUAGES AND ARTS STATE UNIVERSITY OF MEDAN 


\title{
ARTIKEL
}

THEMATIC ANALYSIS OF JUAN SOLANA'S UPSIDE DOWN MOVIE

Disusun dan Diajukan oleh:

Valdy Rifzki

NIM. 2123220038

Telah diverifikasi dan dinyatakan memenuhi syarat untuk diunggah poda jurmal online

\author{
Medan. Juli 2017
}

Menyetujui
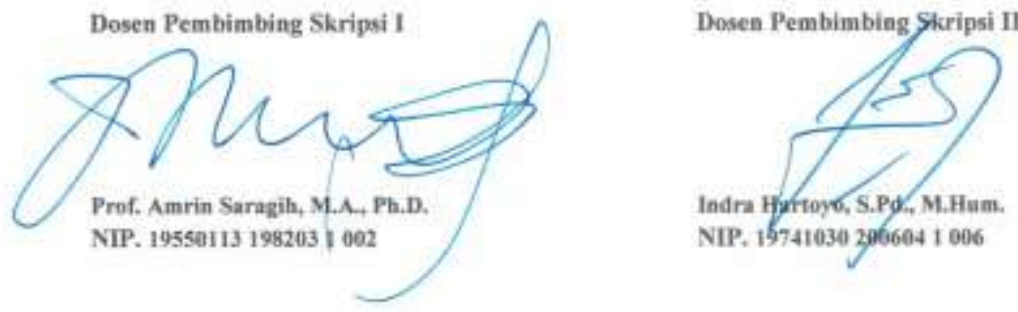

Ka. Program Studi Sastra Ingeris

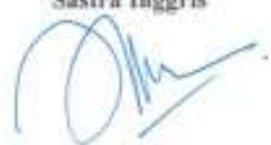

Juli Rachmadani Hasibuaa, S.S., M.Hum. NIP. 198207112008012008 


\title{
THEMATIC ANALYSIS OF JUAN SOLANA'S
}

\section{UPSIDE DOWN MOVIE}

\author{
*Valdy Rifzki \\ ** Prof. Amrin Saragih, M.A., Ph.D. \\ ** Indra Hartoyo, S.Pd., M.Hum.
}

\begin{abstract}
Rifzki, Valdy, 2123220038. Thematic Analysis of Juan Solana's Upside Down Movie, A Thesis, English, Department, Faculty of Languages and Arts, State University of Medan, 2017.
\end{abstract}

The objectives of the study are to investigate and explain about love languages found and used in the Upside Down movie. The data were analyzed by finding the words or statements of main character in the movie script. Chapman's theory of love languages was applied. Based on its form, Chapman divides love languages into 5 kinds, they are (1) words of affirmation, (2) quality time, (3) receiving gifts, (4) acts of service, and (5) physical touch. The method used in this research was descriptive qualitative. The data were analyzed by finding the words or statements by use main character in the movie script. The result shows that, there are four kinds of love languages used. The findings show not all kinds of Love Languages used in the movie. According to the meaning of each kind, Acts of Service wasn't used in the movie because the theme of the movie is about love struggle, and love languages has an important role because the using of it is to build up the relationship.

Keywords: thematic analysis, love languages.

*Graduate Status

** Lecturer Status 


\section{INTRODUCTION}

\section{Background of the Study}

The word love maybe differs from time to time and it depends on individual to imply accordingly one's motive. In fact, everyone in this world has love but most of them not understand about the real meaning of love. It can be different of love in family context and also between two people who don't know each other but emerge of affair.

Love may cover sacrifice, integrity or care for the other people and attention. It is commonly interpreted as the sort of pure love which love is coming up because it is motivated by consideration of good value of love itself. This study will help us to find the truth of love sacrifice. Is the pure love become a motivation for someone to against the challenge.

Generally, literary works are identified with writing works. But nowadays many writing work are expressed in moving picture as known as 'movie'. It becomes popular because more interesting for some people that not like to read the writing works; they choose to watch the movie. It makes easier to understand about the story in a short time. Book or novel must read in a week or more, prepared in moving picture in short time without cutting down the conflict and lesson that consisted in the story.

Nowadays, there are many fiction movies which contain unique story, one of them is "Upside Down". A film by Juan Solanas in 2012, this movie tells about a planet home world which is different from other planets or planetary systems as it is the only one that has "dual gravity". It means the top world is rich and developed region, and in other way also consists of 
romance between two main characters Adam (Jim Sturgess) and Eden (Kirsten Duns), who love each other. Unfortunately, both of them come from different worlds, Adam from lower whereas Eden from upper class. So, Adam has to make every effort to hold his love.

This movie story reflects real life about social class problem. Social class comes as it is different in every aspect. This influences the interaction between them. Some of them feel arrogant and the other desperate. Because of this problem, there are disagreements between individuals or even groups. For someone who falls in love, the problem becomes a challenge to hold their love.

Talking about love, it can be perspective differences. For the example, love at the first sight. Maybe it is impossible for some and the others to believe it. They who have fallen in love at the first sight will believe, although the ending of their love story is sad. Remember not all of the ending of love story is sad but some of them are happy. All of this depends on the effort and the way to resolve the problem. In fact if there's no love in the human life, it is impossible that we are alive in the world.

Not only in the past, nowadays there's also no love without sacrifice, there's no love without difference. This case becomes general problem in every culture, every nation in the world. This problem not also depends on time because the word "Love" grows with time. Love arises for filling a gap. To reach it, an effort and optimism to get love are needed. 
The researcher chooses this movie and this topic because this story describes love at the first sight between a boy and girl of the different classes. Because of their differences so many challenges face them. Although they have been got an accident and finally they can't meet in a long time. Because of the accident Eden has got amnesia so she forgets a lot of things. But that all not be a worry because they struggle with the all of problem faced in front of them.

\section{REVIEW OF LITERATURE}

\section{Literature}

Literature is an interesting subject to be studied. It discusses about the picture of human life. In studying of literature, the reader combine his emotion, imagination, and logical. It helps the reader think personally and intellectually. The word 'literature' is derived from the Latin 'littera' which means 'letter'. It refers to the written of printed words. Literature is a written work and exists in our society as a communicative practice with our social life. By reading literary work, the reader can understand human dreams and struggle in different places and time that he would never otherwise know. Literature itself is a common term related to the fictitious world. Welleck and Warren (1965:94) say that Literature is a social institution using as its medium language, a social creation such as traditional devices as symbolism social arisen only in society. But, furthermore, literature represents life and 
life is, in large measure a social reality even though the natural world and the inner or subjective world of the individual have also been objects of literary imitation.

The explanation above says that literature deals with human life. Some literary works talk about the relation between individual with God, individual with individual, and individual with society. Since their medium is language, they not only can encourage us to assist in producing creative and talented people, but also help those who need recognition and support. The reader can get some moral lessons or motivation for his life by reading literary works. It also tells how we should behave.

\section{Thematic Description and Theme}

A literary work is constructed by intrinsic and extrinsic elements. In this study, focuses on the intrinsic elements. Literary work is more influenced by the intrinsic elements. The intrinsic approach in a literary work consists of five elements, such as theme, plot, setting, character, and point of view. Theme in literary work is one of the constructive elements that construct the literary work but theme can't stand alone, it must contiguous on other constructive elements (plot, setting, character, and point of view).

There are many definitions of theme. Every fiction has a theme, but to understand what is theme is not easy. Commonly, theme does not express explicitly by the author. The reader or audience should read or watch and try to understand what the story tells about. Interpretation is need to get what is the theme. Theme is the central of unifying element of the story which ties 
together all of the other elements of fiction such as plot, setting, character, and point of view that used by the author to tell the story completely.

In literary works, there are usually many separate ideas. When one of the ideas seems to be the major one, it is called the theme. Judith A. Stanford says in her book Responding to Literature: Stories, Poems, Plays, and Essays Fourth Edition (2002:53) says: theme is the central idea that you seek as you read a work think about it. Theme is the meaning of the whole story. Theme as a whole will be closely related to every part and aspect of a story. The writer discovers the theme by a thorough and responsive reading of the story, involving a constant awareness of the relations in every part of it.

\section{Love Languages}

Chapman (1992:3) says that the number of ways to express love within a love language is limited only by one's imagination. The important thing is to speak the love language of your mate. He also concludes five love languages as follows:

\section{Words of Affirmation}

One way to express love emotionally is to use words that build up. Verbal compliments, or words of appreciation, are powerful communicators of love. They are best expressed in simple, straight forward statements of affirmation, such as:

Eden : Uhm... it's a personal project of mine, but... I wanna do it at a much larger scale... but I find your invention could come in handy.

Adam : Wow, that's... That's amazing, really. 
It is not suggesting verbal flattery in order to get your spouse to do something you want. The object of love is not getting something you want but doing something for the well-being of the one you love. It is a fact, however, that when we receive affirming words we are far more likely to be motivated to reciprocate and do something our spouse desires.

Love is kind. If then we are to communicate love verbally, we must use kind words. That has to do with the way we speak. The same sentence can have two different meanings, depending on how you say it. The statement "I love you," when said with kindness and tenderness, can be a genuine expression of love. But how about the statement "I love you?" The question mark changes the whole meaning of those three words. Sometimes our words are saying one thing, but our tone of voice is saying another. We are sending double messages. Our spouse will usually interpret our message based on our tone of voice, not the words we use.

\section{Quality Time}

By "quality time" it means giving someone your undivided attention. A central aspect of quality time is togetherness. It doesn't mean proximity. Togetherness has to do with focused attention.

Quality time does not mean that we have to spend our together moments gazing into each other's eyes. It means that we are doing something together and that we are giving our full attention to the other person. The activity in which we are both engaged is incidental. The important thing emotionally is 
that we are spending focused time with each other. The activity is a vehicle that creates the sense of togetherness. Example:

Eden: Imagine if we could go anywhere we wanted to. I mean, really... Adam: I can imagine that... Hey, you know what?

Eden: What?

Adam: Well, we can. Come on, let's imagine we can, let's go down!

Like words of affirmation, the language of quality time also has many dialects. One of the most common dialects is that of quality conversation. By quality conversation, It means sympathetic dialogue where two individuals are sharing their experiences, thoughts, feelings, and desires in a friendly, uninterrupted context.

\section{Receiving Gifts}

Gifts are visual symbols of love. Visual symbols of love are more important to some people than to others. That's why individuals have different attitudes toward wedding rings. Some never take the ring off after the wedding. Others don't even wear a wedding band. That is another sign that people have different primary love languages. If receiving gifts is her primary love language, she will place great value on the ring you have given to her and she will wear it with great pride. She will also be greatly moved emotionally by other gifts that you give through the years. She will see them as expressions of love. Without gifts as visual symbols, she may question your love.

Gifts come in all sizes, colors, and shapes. Some are expensive, and others are free. To the individual whose primary love language is receiving gifts, the cost of the gift will matter little, unless it is greatly out of line with what you 
can afford. If a millionaire gives only one-dollar gifts regularly, the spouse may question whether that is an expression of love, but when family finances are limited, a one-dollar gift may speak a million dollars' worth of love. Example:

Adam: I got something for you, too... And this is from both worlds. Eden: What is it?

Adam: I can't tell you. You gotta close your eyes. Close your eyes! Come on, like 'closed' closed!

Gifts may be purchased, found, or made. Gifts need not be expensive. It can be a special gift if you can make a unique gift by yourself. They will be excited for your creativity and effort.

\section{Acts of Service}

Such actions as cooking a meal, setting a table, washing dishes, vacuuming, cleaning a commode, getting hairs out of the sink, removing the white spots from the mirror, getting bugs off the windshield, taking out the garbage, changing the baby's diaper, painting a bedroom, dusting the bookcase, keeping the car in operating condition, washing or vacuuming the car, cleaning the garage, mowing the grass, trimming the shrubs, raking the leaves, dusting the blinds, walking the dog, changing the cat's litter box, and changing water in the goldfish bowl are all acts of service. They require thought, planning, time, effort, and energy. If done with a positive spirit, they are indeed expressions of love.

In this part, it is done by husband and wife because it is a commitment between them to do daily activities often according to the agreed schedule. They need discipline from each. 


\section{Physical Touch}

We have long known that physical touch is a way of communicating emotional love.

Physical touch is also a powerful vehicle for communicating marital love. Holding hands, kissing, embracing, and sexual intercourse are all ways of communicating emotional love to one's spouse. For some individuals, physical touch is their primary love language. Without it, they feel unloved. With it, their emotional tank is filled, and they feel secure in the love of their spouse. Example:

Adam: Damn it! Listen, I gotta go.

Eden: No!

OFFICER: Identification!

Adam: I'll find you!

In this act after Adam talks to Eden, he gives her a kiss.

Physical touch can make or break a relationship. It can communicate hate or love. To the person whose primary love language is physical touch, the message will be far louder than the words "I hate you" or "I love you".

So, be careful to do a physical touch to someone. Don't make any mistake if you use your ego and it can make uncomfortable your mate will hate to you.

\section{RESEARCH METHOD}

The study was conducted by applying descriptive qualitative research method. Qualitative research was concerned with developing explanations of social phenomena (Hancock 2009:7). It was concerned with the social aspects 
of our world. Qualitative research also tended to focus on how people or groups of people could have different ways of looking at reality. The method was applied by describing the data and analyzing them through some steps related to the focus of analysis. The reason why the writer chose this method was to explain the problem and analyze through the theory and show the quality through the findings.

In conducting this study, the writer analyzed the love struggle which were found from the main character. Then, the data were described by using Gary Chapman theory to investigate the effort of main character. The source of the data for the study were taken from a movie entitled "Upside Down" with the duration of 110 minutes.

There are some procedures to analyze the data, they are:

1. Transcribe the movie script and choose Adam's dialogue as main character that supported expression of love languages.

2. Sort the data as same as the plot in the movie.

3. Analyze and discussed the significance of the data.

\section{RESULT AND DISCUSSION}

\section{Result}

After analyzing the using of Love Languages in the dialogue of "Upside Down" movie, the findings can be presented as the following: 
1. There are eleven dialogues and three actions (picture) in the movie. It was found that all the data were included in Love Languages but not the all kinds of Love Languages were used in this movie.

2. In using Love Languages, the main character faced many consequences but not the all of findings had the consequences.

\section{Discussion}

The dialogue of Adam as main character in Upside Down movie uses Love Languages to struggle his love with a girl named Eden. Actually, there are 5 kind of Love Languages; Words of Affirmation, Quality Time, Receiving Gifts, Acts of Service, and Physical Touch. But the findings show not all kind of Love Languages uses in the movie.

Adam as the main character uses Words of Affirmation to build up the communication between them, show the anxiety and also wonderfulness of Eden. It is usually supported by tone of voice so the interlocutor feels more comfort and increase the feedback in the conversation.

The using of Quality Time to create the togetherness, it is because togetherness is the central aspect of it. The important thing emotionally is that we spend time with each other. The activity is a vehicle that creates the sense of togetherness. In this movie, because of Adam and Eden are in a relationship so Adam still complies when Eden want to do something that unusual. Although the thing that they do have a seriously risk. They don't 
think what happen after it. The important they can do that thing together and feel happy.

The using of Receiving Gifts is to build up our love to everyone who is special of us. Gifts are visual symbols of love. Visual symbols of love are more important to some people than to others. Gifts may be purchased, found, or made. Gifts need not be expensive. It can be a special gift if you can make a unique gift by yourself. They will be excited for your creativity and effort. In this movie, Adam prepares a gift that he makes by his self. Although, it is seen simple but not everyone can create it because it is an ancient knowledge of his family generation.

The using of Physical Touch is very important in this case because physical touch is a way of communicating emotional love. Physical touch is also a powerful vehicle for communicating marital love. For some individuals, physical touch is their primary love language. Without it, they feel unloved. With it, their emotional tank is filled, and they feel secure in the love of their spouse.

Physical touch can make or break a relationship. It can communicate hate or love. In this movie, when Adam wants to tell the real story between them he tries to hold Eden's hand. Adam thinks when he holds her hand it can build up the love relationship but actually not, it breaks their communication. Because in this situation Eden is amnesia so she feel annoy. But the other 
situation, she has started to remember about the real story of them so when they meet and finally they hug to build up their relationship.

Therefore, be careful to do a physical touch to someone. Don't make any mistake if you use your ego and it can make uncomfortable your mate will hate to you.

The kind of Love Languages that not uses in this movie is Acts of Service. Because this kind of Love Languages is done by husband and wife, it is a commitment between them to do daily activities often according to the agreed schedule. They need discipline from each. It is the reason why in this movie doesn't find the using this kind of Love Languages because in this movie the main character hasn't married and still struggling to his love. 


\section{CONCLUSION AND SUGGESTION}

\section{Conclusions}

After analyzing thematic analysis of Juan Solana's Upside Down movie using Love Languages theory, the researcher has been drawn some conclusion as follow;

It concludes that there are five kinds of Love Languages. Words of Affirmation; Quality Time; Receiving Gifts; Acts of Service; and Physical Touch. The findings show not all kind of Love Languages uses in the movie. According to the meaning of each kind, Acts of Service is not used in the movie because it is usually done by married couple on the other hand the theme of the movie is about love struggle.

It concludes that the theme of the movie is about love struggle, every struggle definitely has consequences. There are many consequences the main character still fights for his love although it is very dangerous for himself. Every effort has he made. But in the end they can be together because their pure love and struggle.

It concludes that the using of love languages by Adam because to build up the relationship and he shows his love to Eden. Meanwhile, in this story Adam must struggle his love so the using of love languages has important role. It is used because the love languages are related to the theme of study. 


\section{Suggestions}

Referring to the results of the study, there are some suggestions as follows:

1. The researcher suggest for the lecturer can give more explanation about literature knowledge especially in literary works which can be analyzed by many aspects.

2. The researcher suggests that the student who wants to know about the literature knowledge especially in love struggle context can use this research as guidance and inspiration.

3. The researcher suggests that the next researcher conduct similar topic of the study with more complete data, different theories of love languages, and more discussion. 


\section{REFERENCES}

Chapman, Gary, 1992. The 5 Love Languages. Chicago: Northfield.

Clements, Robert J. 1978. Comparative Literature as Academic Discipline. New York: The Modern Language.

Erniwati. 2013. Thematic Analysis of New Moon by Stephenie Meyer. Medan: USU.

Gafour, Goran Sabah. 2015. A Thematic Analysis of Online News Stories Framing Democracy in Both Iraq. USA: The University of Kansas.

Hancock, Baverley. 2007. An Introduction of Qualitative Research. Birmingham: University of Birmingham.

Holaman, C Hugh and William Harmon. 1986. A Handbook to Literature. New York:Macmillan.

Knockerboecker, K.L. 1963. Interpreting Literature. New York: Holt Rinehart \& Wiristo Inc.

Kurniasih. Sekar. 2009. An Analysis of Love Values in Charlotte's Bronte novel: Jane Eyre. Medan: USU. Unpublished Thesis.

Nurgiantoro, Burhan. 2007. Teori Pengkajian Fiksi. Gadjah Mada University Press.

Polk, Denise M. and Nichole. 2013. Speaking the Language of Love. USA: West Chester University. Vol.7

Popenoe, David. 1986. Sociology. New Jersey: Prentice-Hall,Englewood Cliffs.

Stanford, Judith A. 2003. Responding to Literature Stories, Poems, Plays and Essays Fourth Edition. New York: Moarch Press.

Welleck, Rene and Warren, Austin. 1965. Theory of Literature. New York: Harcourt, Brave and World Inc. 